\title{
Scope of using jute fiber for the reinforcement of concrete material
}

\author{
Mohammad Zakaria ${ }^{*}$, Mashud Ahmed $^{2}$, Md Mozammel Hoque ${ }^{3}$ and Shafiqul Islam
}

\begin{abstract}
The natural jute fiber can be the effective material to reinforce concrete strength which will not only explore a way to improve the properties of concrete, it will also explore the use of jute and restrict the utilization of polymer which is environmentally detrimental. In Bangladesh, jute is locally available and, hence, less expensive. To achieve this goal, an experimental investigation of the compressive, flexural, and tensile strengths of Jute Fiber Reinforced Concrete Composites (JFRCC) has been conducted. Cylinders, prisms, and cubes of standard dimensions have been made to introduce jute fiber varying the mix ratio of the ingredients in concrete, water-cement ratio, and length and volume of fiber to know the effect of parameters as mentioned. Flexural, compressive, and tensile strength tests have been conducted on the prepared samples by appropriate testing apparatus according to standard specifications. The results of JFRCC were also compared to the plain concrete. The large cut length and higher content of reinforcing materials (jute fiber) result to the unfortunate tendency of balling formation and high porosity of composites followed by the degrading of mechanical properties of JFRCC in reference to plain concrete. But in the incorporation of short and low fiber content, an intact structure develops which enhances the mechanical properties of the same composite. It was also noted that all the remarkable increment values were found mostly in the presence of higher cement content. So it can be concluded that the presence of jute fiber with more cement content strengthens the concrete in greater extent.
\end{abstract}

Keywords: Composites, Reinforcement, Strength, Mechanical properties, Concrete

\section{Background}

The sustainable development with higher strength is the growing demand of construction industry. Concrete reinforcement by natural fibers are more promising to insure the concrete strength improvement with nonhazardous impact on environment as well as the effective use of available natural assets. To achieve this goal, numerous researchers have used the fiber as well as yarn very effectively as a concrete reinforcing material (Thakur et al. 2014; Balaguru and Shah 1992; Barr et al. 1996; Meddaha and Bencheikh 2009; Rizkalla and Hassan 2002; Zakaria, et al. 2015). The fibers can insure the postcracking resistance, high-energy absorption features, and increased fatigue resistance of cement-based composites (Savastano et al. 2009). Among two different types of

\footnotetext{
* Correspondence: zakariate@duet.ac.bd

'Department of Textile Engineering, Dhaka University of Engineering \&

Technology, Gazipur, Bangladesh

Full list of author information is available at the end of the article
}

fibers, i.e., natural fibers and artificial polymer-based fibers, natural fibers are promising to use as reinforcement to overcome the inherent deficiencies in FRCC reinforced with polymer-based fiber (Ramakrishna and Sundararajan 2005). The main deficiencies associated with the use of artificial fibers are relatively high cost and health and environmental hazards.

On the contrary, natural fibers which are biodegradable, inexpensive, environmental friendly, and easily available as reported by Xie et al. (2010) are produced from naturally available resources, for instance, coconut tree, banana tree, cotton, and jute. Researchers have conducted numerous studies on the effect of natural fibers on the mechanical and physical behavior of concrete to investigate the extent of improvement. In recent years, unrelenting efforts have been observed for using natural fibers in FRCC for improving the energy efficiency, economy, and eco-friendliness flavor (Ramakrishna and Sundararajan 2005). Hence, the demands to utilize natural fibers for making good-quality and low- 
cost sustainable FRCC for housing and other necessities are increasing. Additionally, the other potential application of natural fiber-reinforced cement composites are limited to those area where energy are to be absorbed or the areas prone to impact damage. Accordingly, natural fiber-reinforced cement composites are most suitable for shatter- and earthquake-resistant construction, foundation floor for machinery in factories, fabrication of lightweight cement-based roofing and ceiling boards, wall plaster, and construction materials for low-cost housing (Aziz et al. 1981). Variety of factors influences mechanical properties of FRCC reinforced with natural fiber. The factors are characteristics of fibers, nature of the cement-based matrix, and the way of mixing, casting, and curing the composite (Aziz et al. 1981). Among these parameters, the type of fiber and their characteristics have a significant influence on the mechanical properties of these composites (Jarabo et al. 2012). Jute fibers, which come from annual plants, are available in plenty in Bangladesh. It is a prospective material for cementbased matrix.

According to the previous study (Mansur and Aziz 1982; Chakraborty et al. 2013; Meddaha and Bencheikh 2009; Bezerra et al. 2004), a number of difficulties are encountered while mixing natural fibers to produce composite. For instance, Meddaha and Bencheikh (2009) mentioned that inhomogeneous distribution of fibers yields bulk and surface flaws. The stress concentration at these flaws would accelerate crack propagation which results to lower fracture strength of the mortar specimens (Bezerra et al. 2004). Chakraborty et al. (2013) also reported to use natural fibers in FRCC that the agglomeration could not be avoided. The amount of fibers that can be added to a mix is limited by the tendency of "bailing" (Mansur and Aziz 1982) where the fibers frequently intermesh and form fiber balls which is critical to be separated. The bailing of fibers results in an ineffectual and segregated mix which produces a highly porous and honeycombed concrete. As a result, a remarkable strength fall of the concrete composite occurs. From the above elucidation, it can be concluded that the fiber mixing plays a vital role in the perfection of mechanical properties of fiber-reinforced concrete composites. Additionally, the use of natural fibers in concrete made with crushed stone has been universally used. The use of crushed bricks are very common (Rashid et al. 2009) in Bangladesh, parts of India, and some other countries having scarcity of stone. Additionally, the mechanical properties of concrete made with crushed bricks are quite different than those made with crushed stone (Mansur et al. 1999; Mohammed et al. 2014). Investigative studies have not yet been conducted to evaluate the effect jute fiber on the concrete made with crushed bricks.
To this end, it is very much rationale to determine the effect for exploring potential use of jute for obtaining enhanced concrete with low cost, without affecting the environment and minimum health hazard. With this background, the main objective of the study is to develop jute fiber to reinforce concrete composites and to investigate the effect of fiber length and content (volume fraction) on its mechanical behavior.

\section{Methods \\ Materials}

The locally available raw jute fiber shown in Fig. 1 was used without any treatment. This jute fiber with four different cut lengths $(10,15,20$, and $25 \mathrm{~mm})$ also shown in Fig. 2 were applied with various volumetric percentages on concrete mixture. Ordinary Portland cement was applied as a binding material; the normal consistency of which was $30 \%$, the initial setting time was $132 \mathrm{~min}$, and the final setting time was 0700 hours. Sand (Fineness modulus $=2.5$ ) and $25-\mathrm{mm}$ down well-graded crushed bricks were used as coarse aggregate.

\section{Concrete mix}

Mix design is the selection of mix ingredients and their proportions required in a concrete mix. The mix design involves that amount of cement, fine aggregate, and coarse aggregate (Brick chips, shown in the Fig. 3) be available and the relation between water/cement ratio and target strength must be known. Since, the objective of the study is to investigate the effect of incorporating jute fiber on the mechanical properties of concrete, the mix design with target strength was not accomplished in the study. Rather, the commonly practiced mix ratio used in Bangladesh and other neighboring countries like parts of India and Pakistan was used. To this end, in the present study, two different mix ratios, cement/sand/ brick chips (by volume) $=1: 2: 4$ and 1:1.5:3 and water/cement ratio (by weight) 0.60 and 0.55 , were cautiously maintained. In concrete mix preparation, initially different jute fiber cut length and volumetric content were

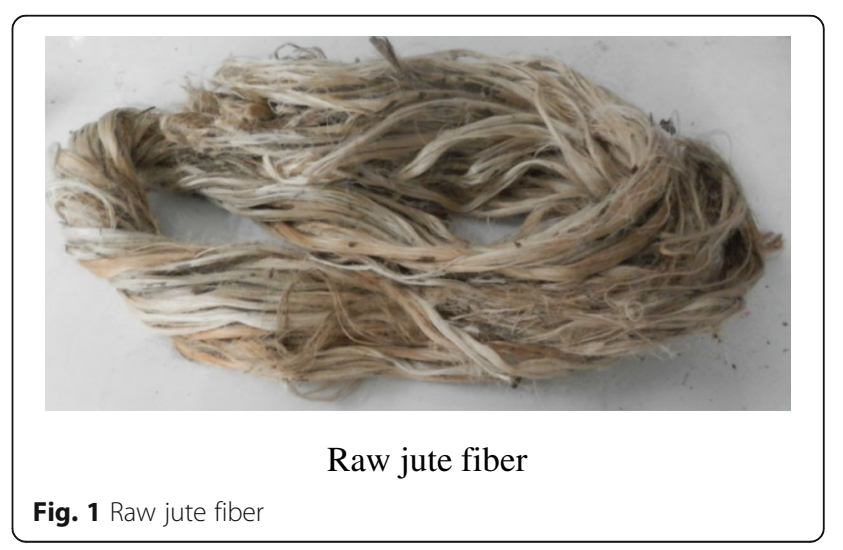




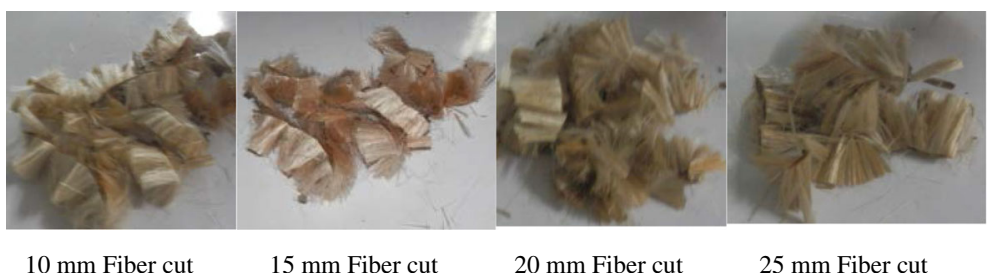

Fig. 2 Cut lengths of raw jute fiber

applied in the concrete mix and observed in the mixing performance to obtain better arrangement of jute. And finally, jute fiber of 10-, 15-, 20-, and 25-mm lengths with $0,0.1,0.25,0.50$, and $0.75 \%$ volume dosing were selected; and lastly, samples were prepared for a particular set of parameters. Table 1 shows the calculated amount of materials for a single variable, where others can be achieved by the same procedure.

\section{Preparation of the test specimen}

The different parameters of the concrete composites, the length, and volume fraction of the jute fiber content were used. The different lengths of fiber 10, 15, 20, and $25 \mathrm{~mm}$ and the contents $0,0.1,0.25,0.50$, and $0.75 \%$ were used. Three different specimens: cubes $(150 \mathrm{~mm} \times$ $150 \mathrm{~mm} \times 150 \mathrm{~mm})$, prisms $(450 \mathrm{~mm} \times 150 \mathrm{~mm} \times$ $150 \mathrm{~mm})$, and cylinders $(150 \mathrm{~mm} \times 300 \mathrm{~mm})$ were cast to determine the compressive, flexural, and tensile strength of the composites, respectively. The fibers were cut to the mentioned length manually by a hand scissor. The mixing of the ingredients were done by a pan mixer accordingly and jute fibers were added slowly and evenly to the concrete mix, so that a uniform distribution of yarns throughout the concrete could be confirmed. Cement was added into the mixer and mixing was conducted followed by the addition of water, until

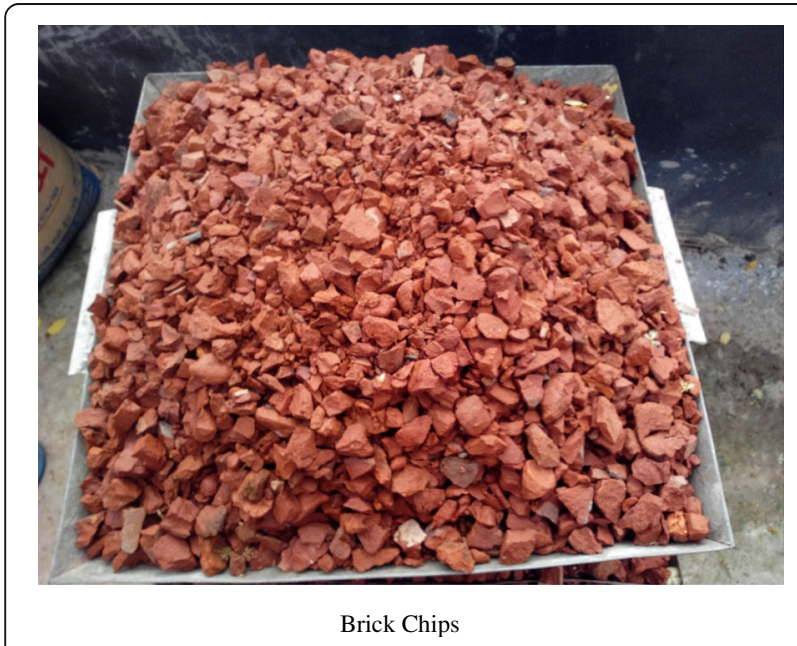

Fig. 3 Brick chips uniformity was achieved. This way of concrete mixing was continued for about $3 \mathrm{~min}$. Then, the freshly mixed concrete was poured in the molds of cube, prism, and cylinder. After that, the specimens were left $24 \mathrm{~h}$ for demolding. They were then cured in water for at least 28 days. At the end of the curing period, the specimens were allowed to be dried in air for $24 \mathrm{~h}$ before testing.

\section{Experimental program}

The present study consists of determining the flexural, compressive, and tensile strength of concrete composites with jute fiber and was compared to those of the plain concrete. A Universal Testing Machine (Model-UTN100, India, capacity $980 \mathrm{KN}$.) for tensile test and an Automatic Compression Testing Machine (MATEST s.r.l, Italy, capacity 3000 KN.) shown in Fig. 4 for compressive test and an Automatic Flexural Strength Testing Machine (MATEST s.r.l, Italy, capacity 150 KN.) for flexural test were used. In addition, the microscopic views of the tested specimens were also analyzed.

\section{Compressive strength testing}

Compressive strength of a concrete is a measure of its ability to resist static load, when the latter one tends to crush it. Testing of compressive strength is the most common; many desirable characteristics of concrete are related to its strength, and hence, the compressive strength of concrete in structural design is of utmost importance. Additionally, the compressive strength gives a good and clear indication on how the strength is affected with the increase of fiber volume dosage rate in the test specimens. In AS 1012, it is mentioned that the specimens for compressive strength should be $150 \mathrm{~mm}$ diameter and $300 \mathrm{~mm}$ height, but this only applies to the maximum aggregate size more than $20 \mathrm{~mm}$ while the cube specimen with $150 \mathrm{~mm}$ in each side (AS 1012 2002), and the intensity of load is determined in megapascal qualitatively. The compression test procedure was carried out according to test method AS 1012.9.

\section{Flexural strength testing}

Flexural strength of a concrete is a measure of its ability to resist bending, and it can be expressed in terms of modulus of rupture. Therefore, the two-point loading 
Table 1 Amount of various materials for preparation of a Prism with mix ratio 1:2:4

\begin{tabular}{|c|c|c|c|c|c|c|c|c|}
\hline \multirow{2}{*}{$\begin{array}{l}\text { Sample } \\
\text { no. }\end{array}$} & \multirow{2}{*}{$\begin{array}{l}\% \text { of } \\
\text { fiber or yarn } \\
\text { (as volume) }\end{array}$} & \multirow{2}{*}{$\begin{array}{l}\text { Total } \\
\text { volume } \\
\left(\mathrm{cm}^{3}\right)\end{array}$} & \multicolumn{3}{|c|}{ Volume of cement and aggregates $\left(\mathrm{cm}^{3}\right)$} & \multirow{2}{*}{$\begin{array}{l}\text { Volume } \\
\text { of jute } \\
\left(\mathrm{cm}^{3}\right)\end{array}$} & \multirow{2}{*}{$\begin{array}{l}\text { Specific } \\
\text { gravity of jute } \\
\left(\mathrm{gm} / \mathrm{cm}^{3}\right)\end{array}$} & \multirow{2}{*}{$\begin{array}{l}\text { Weight } \\
\text { of jute } \\
\text { (gm) }\end{array}$} \\
\hline & & & Cement & Sand & Brick chips & & & \\
\hline 1 & 0 & $10,618.82$ & 1516.97 & 3033.95 & 6067.90 & 0.00 & 1.46 & 0.00 \\
\hline 2 & 0.1 & & 1515.46 & 3030.91 & 6061.83 & 10.62 & & 15.50 \\
\hline 3 & 0.25 & & 1513.18 & 3026.36 & 6052.73 & 26.55 & & 38.76 \\
\hline 4 & 0.5 & & 1509.39 & 3018.78 & 6037.56 & 53.09 & & 77.52 \\
\hline 5 & 0.75 & & 1501.80 & 3003.61 & 6007.22 & 106.19 & & 155.03 \\
\hline
\end{tabular}

method was used in making flexural strength tests of concrete employing bearing blocks which ensured that forces applied to the beam was perpendicular to the face of the specimen and was applied without eccentricity. During test, the reaction was always parallel to the direction of applied force. The test procedure was carried out following the test method ASTM C 78-00. The distance of the loading point (l) is $133 \mathrm{~mm}$ and the supporting point (L) is $400 \mathrm{~mm}$ whereas the load was applied continuously and without any shock at a constant rate to the breaking point. Apply the load at a rate that constantly increases the extreme fiber stress $1.21 \mathrm{MPa} /$ min. Finally, results were obtained in the form of total load in kilonewton and intensity of load in megapascal.

\section{Tensile strength testing}

Investigation of concrete's mechanical properties can be presented reasonably through the analysis of tensile strength. The brittleness and low tensile strength of concrete make it abortive to struggle with the direct tension. Hence, the measurement of tensile strength is obligatory to determine the load at which the concrete members may crack; therefore, the cracking is due to the tension failure. The splitting tests (sometimes referred to as split tensile strength tests) are well-known indirect tests used

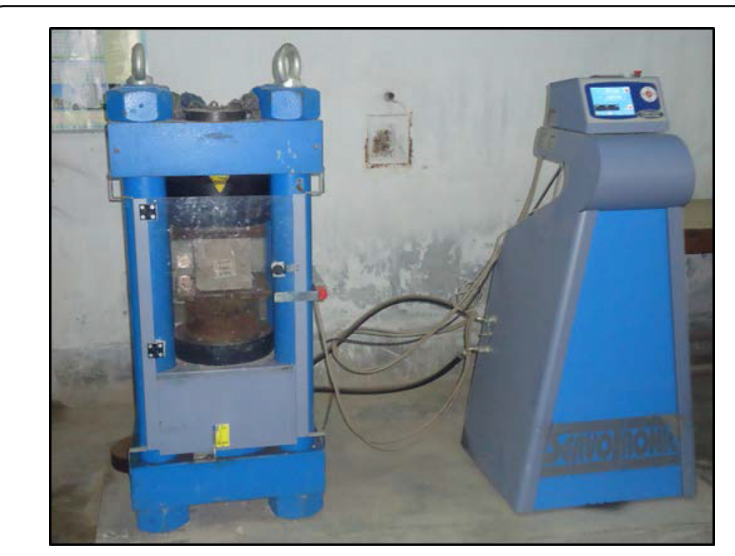

Automatic Compression Testing Machine (MATEST s.r.l.)

Fig. 4 Automatic Compression Testing Machine (MATEST s.r.l.) for determining the tensile strength of concrete. The test procedure consists of applying a compressive line load along the opposite generators of a concrete cylinder placed with its axis horizontal between the compressive planes. The splitting tensile strength test was conducted according to the test method ASTM C 496/M496.

\section{Results and discussion}

The mechanical behavior of fiber-cement composite, which basically accounts for the bond between fiber and surrounding concrete, largely depends on many factors like the physical characteristics of the fibers such as geometry, type and surface characteristics, fiber orientation, fiber volume ratio and fiber distribution, the chemical composition of the fiber, and so on. Tests were conducted to evaluate the effect of jute fiber, and results are presented diagrammatically in figures (Figs. 5, 6, 9, 10,11 , and 12).

\section{Compressive strength}

Figures 5 and 6 illustrate the deviation percentage of compressive strength of Jute Fiber Reinforced Concrete Composites (JFRCC) to plain one with respect to four different volumetric dosing of jute fiber in two different mix ratios 1:1.5:3 and 1:2:4, respectively. Where the plain concrete are manufactured without any jute fiber from two figures, it can be stated that the remarkable enrichment of compressive strength is observed only for 10 and $15 \mathrm{~mm}$ fiber cut with $0.10 \%$ volumetric content; however, the $25-\mathrm{mm}$ fiber length causes the maximum strength loss of concrete composites. For $15-\mathrm{mm}$ fiber length, $15 \%$ increment of compressive strength is observed with $0.10 \%$ dosing in 1:1.5:3 mix ratio whereas for another mix ratio, $10 \%$ enhancement is visualized with the same fiber length and content. Therefore, an impact of mix ratio on composite strength is uncovered, higher cement content causes the proper mixture of concrete as well as the more enhancement of strength. In the presence of more cement, fiber can be dispersed through the concrete mixture evenly and the regular arrangement of fiber can be attained which constructs more resistive composite material in contradiction with 


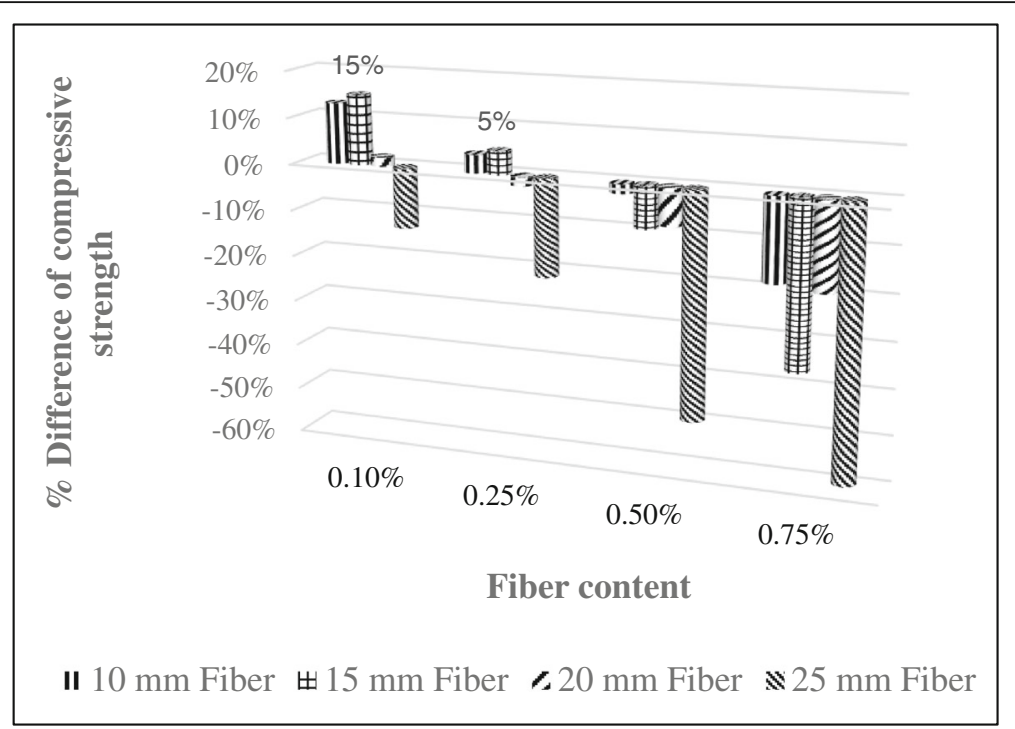

Comparison of compressive strength with 1:1.5:3 mix ratio.

Fig. 5 Comparison of compressive strength with 1:1.5:3 mix ratio

functional force. In both mix ratios, 10-mm fiber exhibits the second most strength improvement of JFRCC with $0.10 \%$ dosing. An unexpected decrement of compressive strength is occurred due to the inclusion of higher fiber length $(20$ and $25 \mathrm{~mm})$ and content $(0.25$, 0.50 , and $0.75 \%$ ).

Since numerous studies have considered reinforcing materials, i.e., fibers or yarns as similar to coarse aggregate, the inclusion of jute yarn leads to an increase of coarse aggregate fraction in spite of the fine aggregate fraction which could result in a high porosity in the cement matrix. A decreasing trend with fiber content can be explained that with the addition of jute yarn in concrete reduces the specific gravity of the composites and due to the low specific gravity, inadequate mixing, and high porosity of the JFRCC, a lower compressive strength with respect to the reference concrete particularly, when a high volume and larger length of yarn was added. Similar results were obtained by Shimizu et al. (1992). Concrete mixing with large fiber cut and higher content are also blamed to discontinuous distribution of materials which creates the low strength areas in the composite specimen. Balaguru and Shah reported that fibers that are long and at higher volume fractions were found to ball up during the

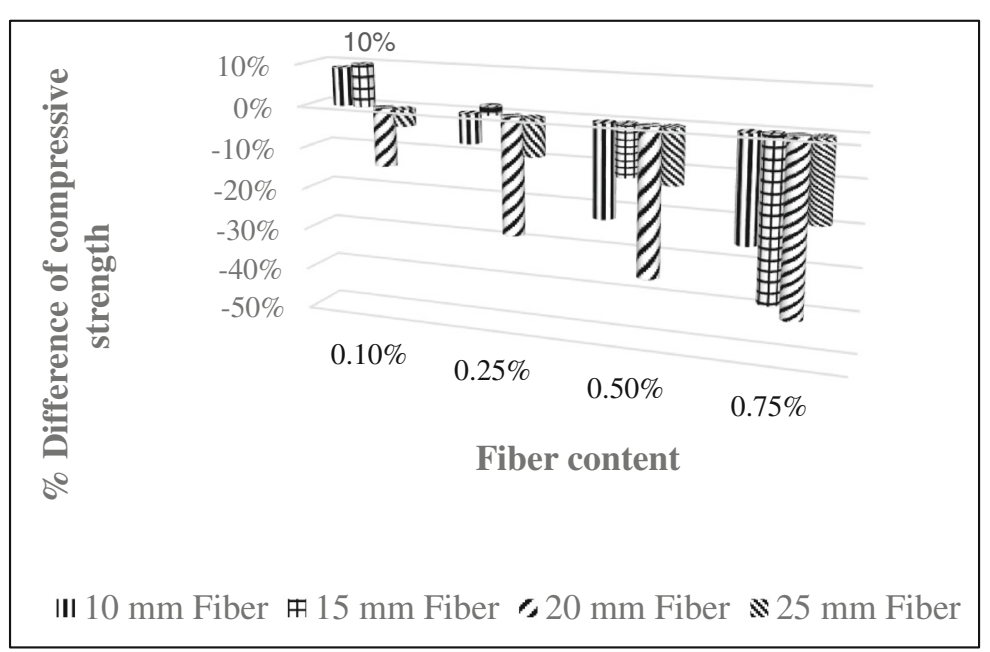

Comparison of compressive strength of JFRCC with 1:2:4 mix ratio.

Fig. 6 Comparison of compressive strength of JFRCC with 1:2:4 mix ratio 
mixing process (Balaguru and Shah 1992). The process called "balling" occurs and causes the concrete to become stiff and a reduction in workability with increased volume dosage of fibers. Finally, it can be said that JFRCC with $<15-\mathrm{mm}$ fiber cut length with $\leq 0.10 \%$ volumetric dozing is the more promising combination for compressive strength increment.

Figures 7 and 8 show the failure specimens of the sample after tests. In the case of control specimen, it was seen that the crack propagates rapidly with a regular manner while the cracks were observed to run in multidirectional path for JFRCC. This is possible through stress transfer across the cracks, and the fiber arrests the rapid crack propagation and prolongs the strain life to continue beyond the ultimate.

\section{Flexural strength}

Figures 9 and 10 represent the amendment of flexural strength of JFRCC made with two different mix ratios (1:1.5:3 and 1:2:4) as a percentage in relation to the plain concrete. It can be reported that the variable of JFRCC is made by incorporating jute fiber in four different lengths $(10,15,20$, and $25 \mathrm{~mm})$ with its volumetric dozing $0.10,0.25,0.50$, and $0.75 \%$ for both mix ratios. In case of flexural strength, the same outcome was observed as the shorter fiber length and lower contentreinforced concrete strength greatly whereas more fiber content and larger length resulted the easy failure of concrete. The highest strength augmentation up to 22 and $14 \%$ was achieved for $15-\mathrm{mm}$ fiber of $0.10 \%$ dozing with mix ratio 1:1.5:3 and 1:2:4, respectively. Mixing of concrete low cut length's jute fiber can move easily and causes the even spreading of fiber and create the better reinforcement on composites. However, the higher porosity and uneven distribution of reinforcing material causes the heavy reduction of bending strength due to

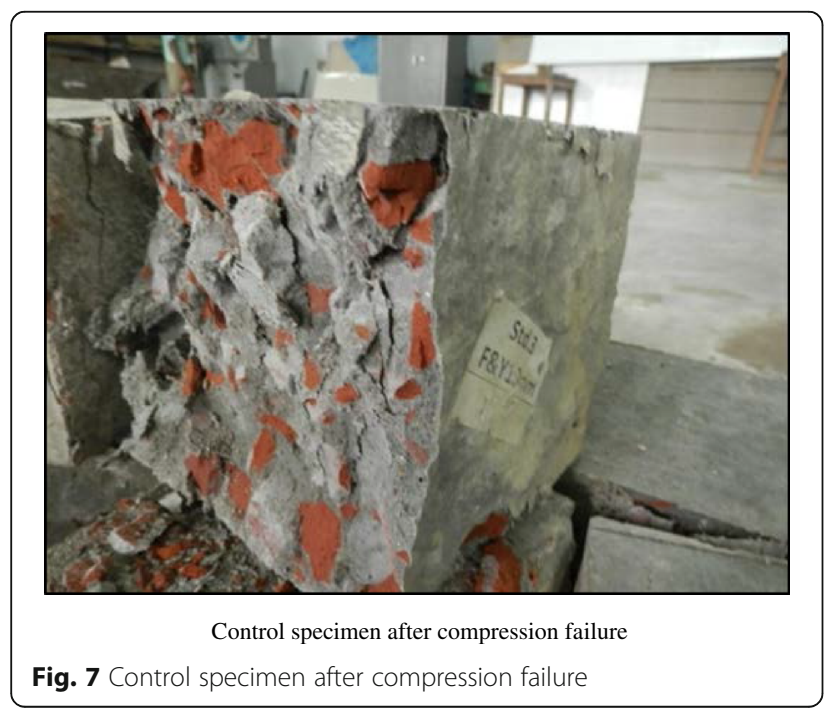

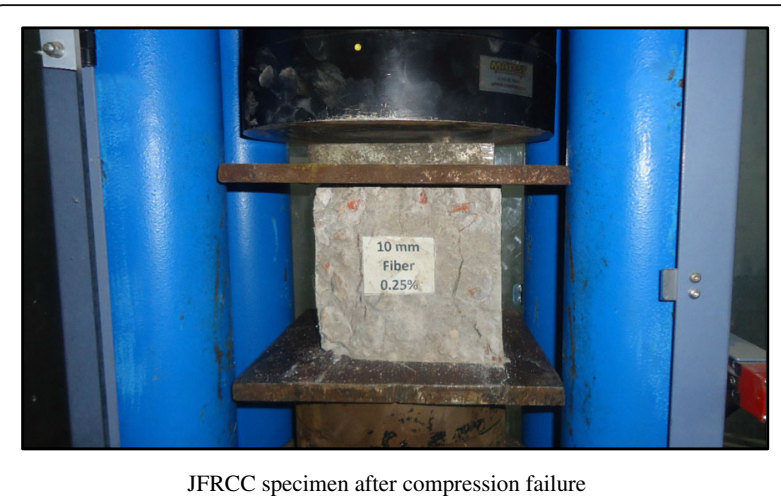

Fig. 8 JFRCC specimen after compression failure

$>15$-mm fiber length and $>0.25 \%$ volumetric dozing; the maximum drop was found to be $69 \%$ lower than that of the plain concrete. Moreover, the inclusion of more jute of larger length results to the discontinuity of concrete mixing and improper arrangement of the concrete constituents that highly affect the strength against bending of a prism specimen. Similar trend has also been observed regarding the incorporation of fiber in concrete by Meddaha and Bencheikh (2009). Failure of such beam specimen is initiated by the formation of cracks that would proceed along the pre-weak zones with smaller cracking load as compared with the intact specimen or with specimen with lower yarn content. The matted condition of concrete mixture is irradiated by using low reinforcing material cut length and jute spun yarn as reinforcing material.

\section{Tensile strength}

The tensile strength improvement percentages of JFRCC with respect to plain concrete (0\% jute) are shown in Figs. 11 and 12 for mix ratios 1:1.5:3 and 1:2:4, respectively. Here, the different cylindrical specimens were prepared by using jute fiber as a reinforcing material of various cut lengths $(10,15,20$, and $25 \mathrm{~mm})$ with $0,0.25$, 0.50 , and $0.75 \%$ volumetric dozing in both mix ratios. The highest strength increment was found for cylinder failure against tensile load. Here also, the shorter jute with lower content is more promising than the longer fiber with more amount for concrete reinforcement. The maximum enhancement was achieved $35 \%$ for $15-\mathrm{mm}$ fiber with $0.10 \%$ volumetric dozing in reference to plain concrete in the case of 1:1.5:3 mix ratio. The short fiber cut with lower content influences the proper distribution of fiber and resist cracking the cylinder against tensile load. The multiple crack was found in the cylindrical specimen during tensile failure of JFRCC while plain concrete exhibits the single and rapid crack, thus the composite shows the enriched tensile value up to fiber content $0.25 \%$. The contribution of the jute fiber is 


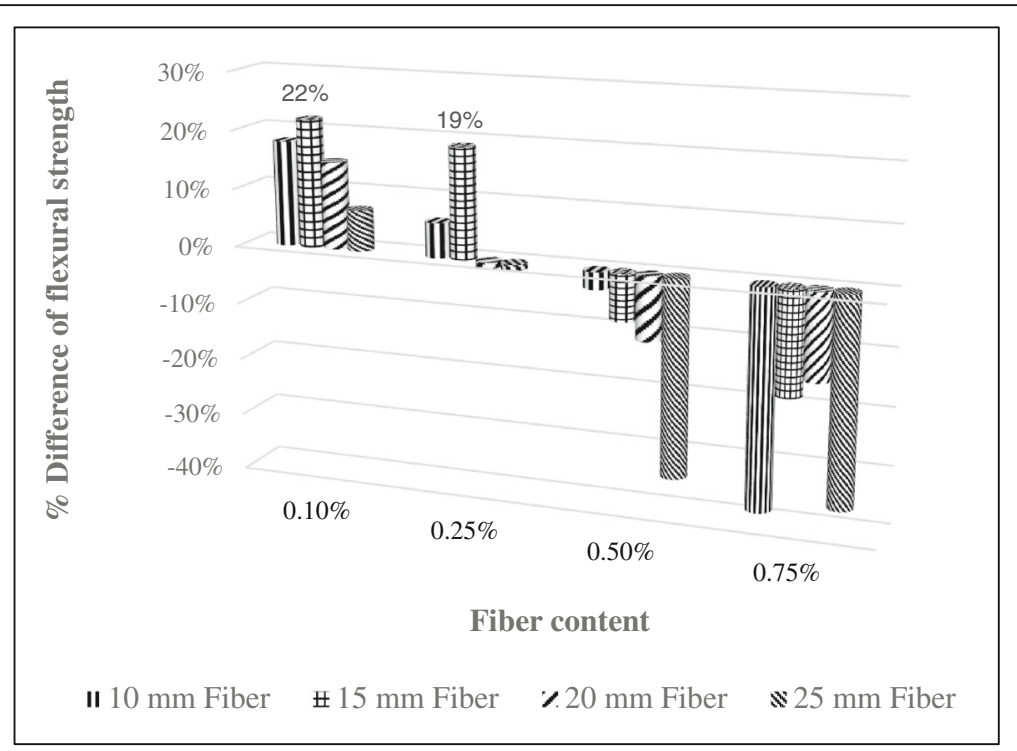

Comparison of flexural strength of JFRCC with 1:1.5:3 mix ratio

Fig. 9 Comparison of flexural strength of JFRCC with 1:1.5:3 mix ratio

observed on the ability of JFRC composite to maintain the ultimate load through further deflection without sudden collapse. However, the concrete tensile strength reduction was observed for $>15 \mathrm{~mm}$ fiber length and $>0.50 \%$ dosing. Larger fiber content yields more voids in the concrete due to the lack of free reorganization of the concrete matrix as a result of the reduced workability and balling effect during vibration and casting of the specimens. Schrader (1978) mentioned that the first crack load of FRC depends basically on the amount, length configuration, strength, and ductility of fibers, whereas cement content and aggregates are less responsible in this concern.

\section{Analysis the microscopic view of JFRCC}

Microscopic images of failed JFRCC specimen were taken and shown in Figs. 13 and 14. From the microscopic view, visual analyses were done. Images taken on crack parts of sample shows the presence of randomly distributed jute fiber which caused the increment of

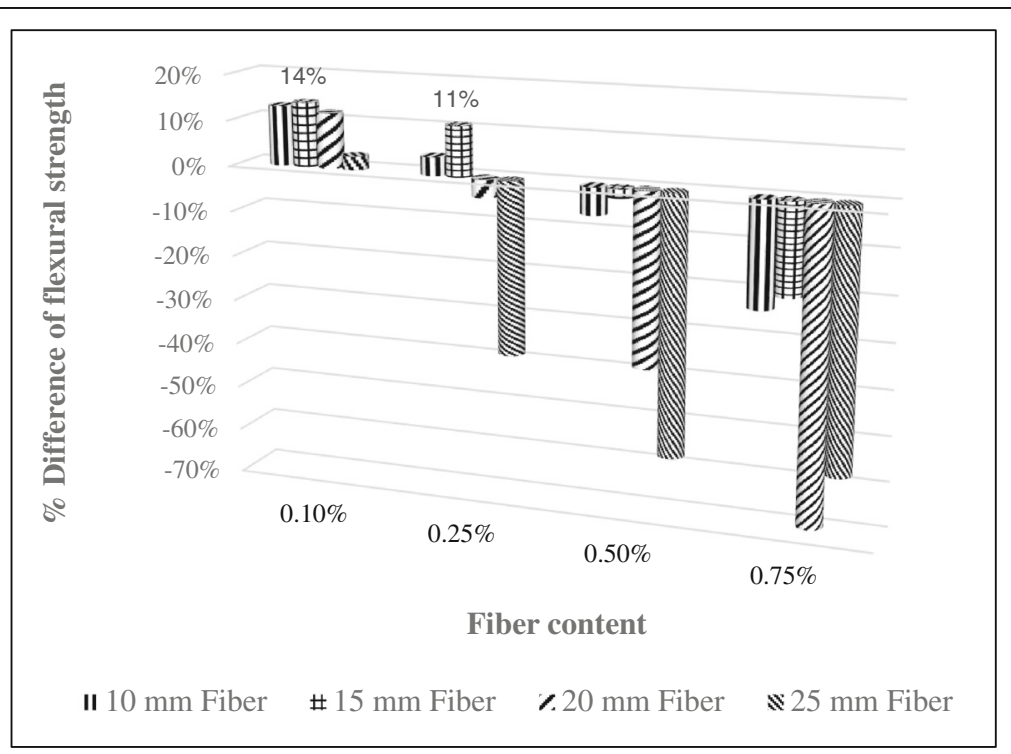

Comparison of flexural strength of JFRCC with 1:2:4 mix ratio.

Fig. 10 Comparison of flexural strength of JFRCC with 1:2:4 mix ratio 


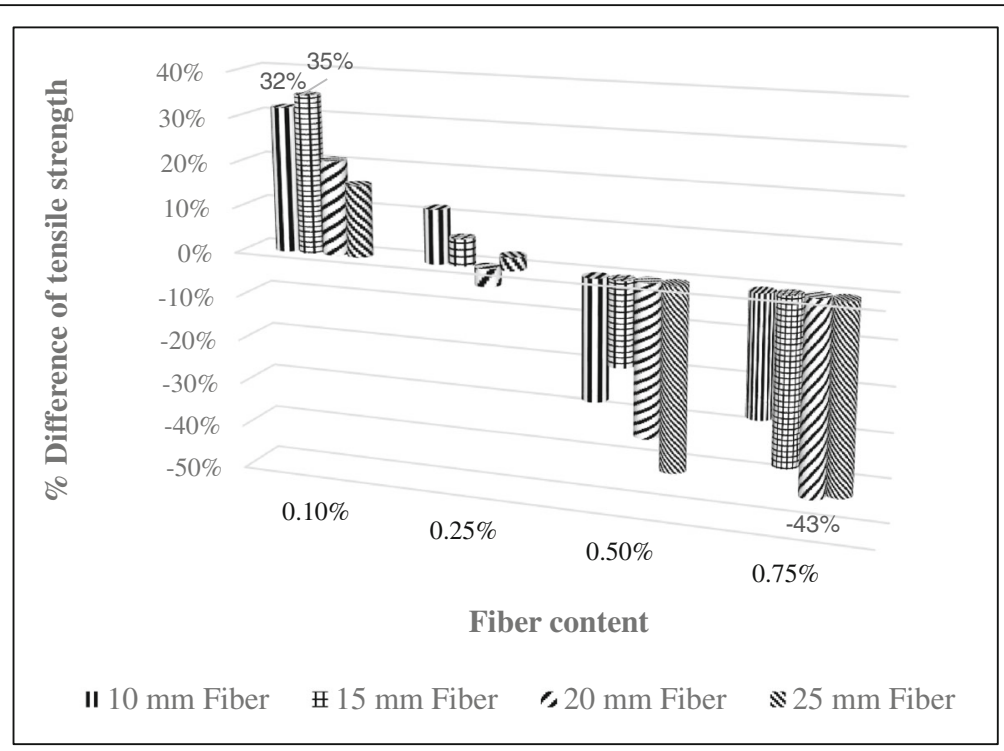

Comparison of tensile strength of JFRCC with 1:1.5:3 mix ratio.

Fig. 11 Comparison of tensile strength of JFRCC with 1:1.5:3 mix ratio

strength of JFRCC. Fractured ends of jute fiber appeared in the specimen that showed the largest strength enhancement. From the observation, it would be stated that the adequate bonding between jute fiber and concrete causes the fiber breakage at the cracked line that is why JFRCC expressed the strength augmentation with reference to plain concrete. It can also be visualized that the jute fiber resists crack in different angles and brace it that is absent in plain concrete. For this reason at the time of failure of various tests, the JFRCC specimen is not discrete properly, but for plain concrete, it would be separated very quickly and it may convey better results for developed earthquake-resistive structure.

\section{Conclusions}

Concrete with jute fiber is an aspiring step towards the sustainable development in Bangladesh where the jute are abundantly cultivated. In the experimental investigations

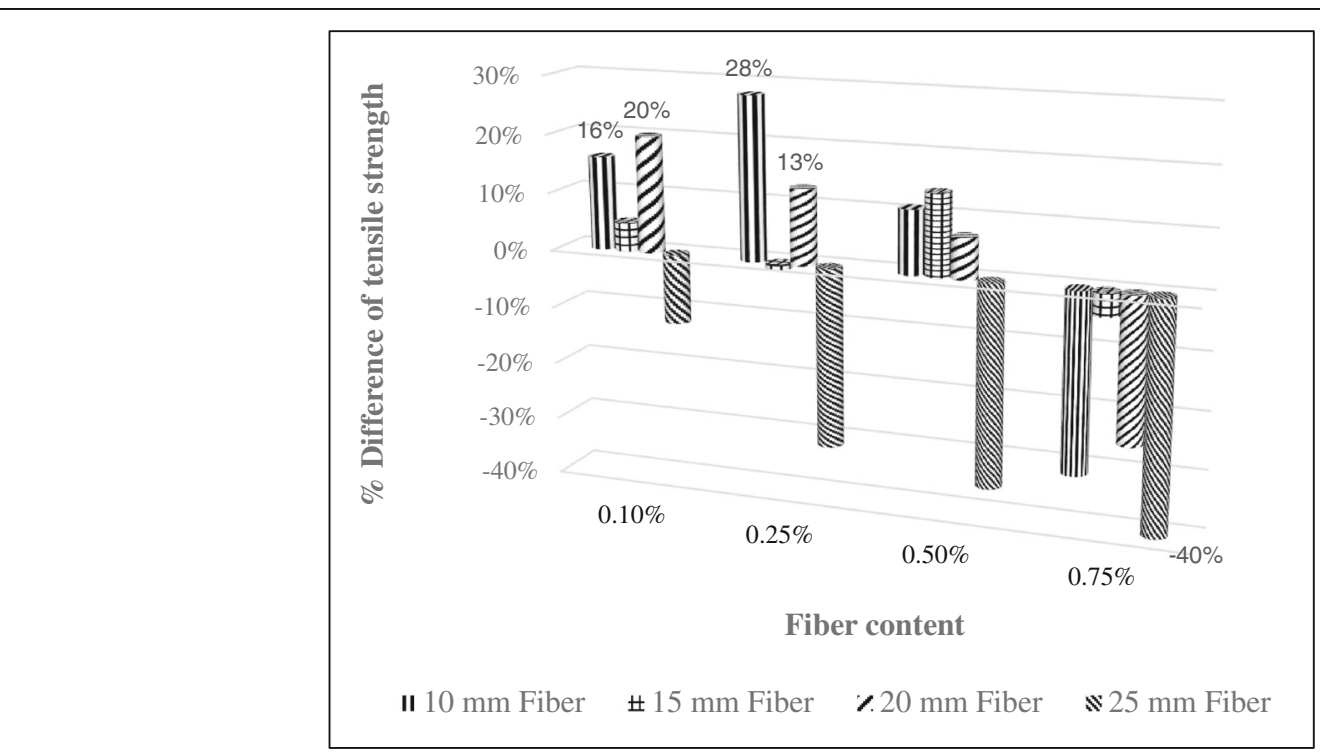

Comparison of tensile strength of JFRCC with 1:2:4 mix ratio.

Fig. 12 Comparison of tensile strength of JFRCC with 1:2:4 mix ratio 


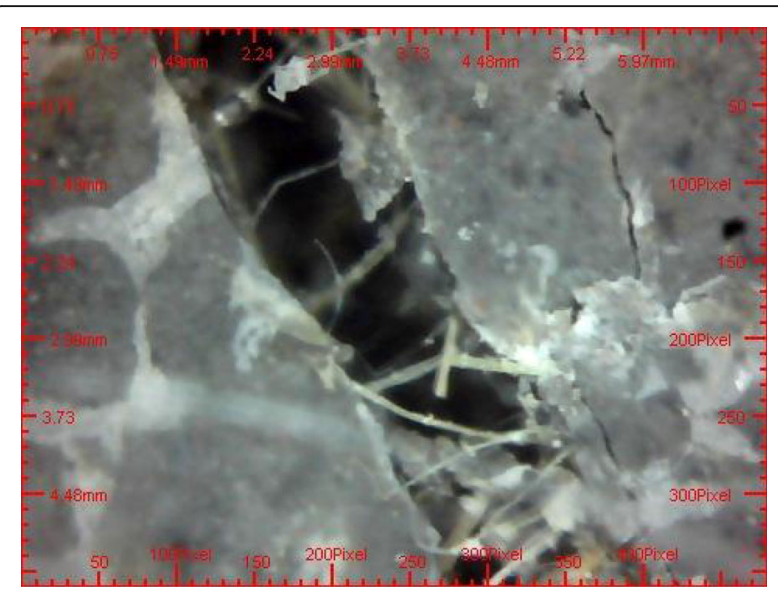

Microscopic image (X50) of crashed JFRCC after compression test.

Fig. 13 Microscopic image $(\times 50)$ of crashed JFRCC after compression test

conducted in the study, it was found that the addition of jute fiber contributes enriched results for mechanical properties of concrete composites for a particular length and content of fiber. More specifically, compressive, flexural, and tensile strength are found to enhance significantly for volume content of 0.1 and $0.25 \%$ and the fiber cut length of 10 and $15 \mathrm{~mm}$. However, with larger fiber length and content, the mechanical properties were found to affect adversely. Finally, it can be stated that the maximum increment is observed for tensile strength which is $35 \%$ with reference to the plain concrete. So JFRCC can be developed with locally fabricated jute in Bangladesh. The least cost of jute, its being renewable resources, the reduced weight of the JFRCC, and the environmental compatibility would clearly show the socioeconomic viability of JFRCC. Based on the insights gained from the test

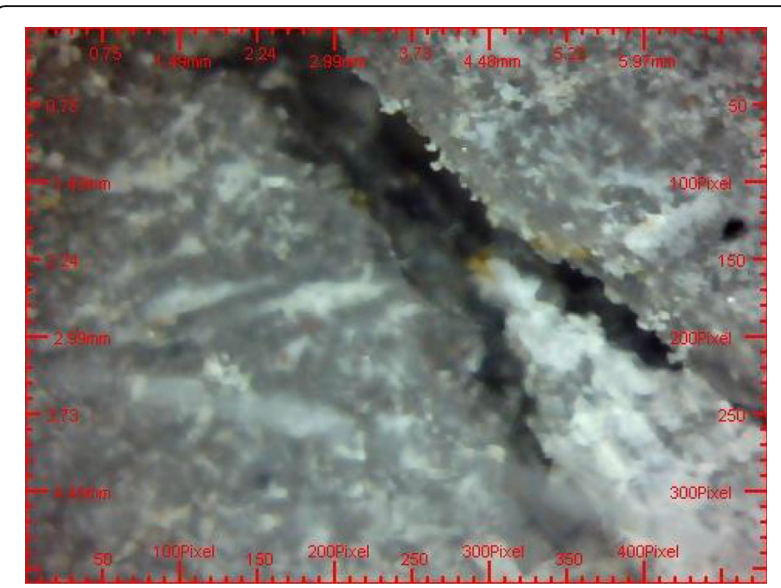

Microscopic image (X50) of crashed plain concrete after compression test.

Fig. 14 Microscopic image $(\times 50)$ of crashed plain concrete after compression test results and analyses of the JFRCC, the incorporation of jute fiber in making FRC composite would be one of the promising strategies to improve the performance of concrete.

\section{Authors' contributions}

$M Z$ conceived of the study, performed the instrumentation of the specimens and contributed to the manuscript. MZ and SI interpreted data, drafted the manuscript and coordinated its submission. $\mathrm{MH}$ contributed to the data analysis and drafting of the manuscript. MA conceived of the study and the experimental design and contributed to the manuscript. All authors read and approved the final manuscript

\section{Competing interests}

The authors declare that they have no competing interests.

\section{Author details}

${ }^{1}$ Department of Textile Engineering, Dhaka University of Engineering \& Technology, Gazipur, Bangladesh. ${ }^{2}$ Department of Fabric Manufacturing Engineering, Bangladesh University of Textiles, Dhaka, Bangladesh. ${ }^{3}$ Department of Civil Engineering, Dhaka University of Engineering \& Technology, Gazipur, Bangladesh.

Received: 25 August 2016 Accepted: 14 September 2016 Published online: 01 December 2016

\section{References}

AS 1012. (2002). Compressive test of concrete specimen, methods of testing concrete, Standards Australia.

Aziz, M. A., Paramasivam, P., \& Lee, S. L. (1981). Prospects for natural fibre reinforced. The International Joumal of Cement Composites and Lightweight Concrete, 3(2), 123-132.

Balaguru, P. N., \& Shah, S. P. (1992). Fibre-reinforced cement composites. New York: Macgraw-Hill.

Barr, B., Gettu, R., Al-Oraimi, S. K. A., \& Bryars, L. S. (1996). Toughness measurement-the need to think again. Cement \& Concrete Composites, 18(4), 281-297.

Bezerra, EM, Joaquim, AP, Savastano Jr, H (2004). Some properties of fibrecement NOCMAT 2004 conference. Pirassununga, Brasil: 1-11.

Chakraborty, S., Kundu, S. P., Roy, A., Basak, R. K., \& Adhikari, B. (2013). Improvement of the mechanical properties of jute fibre reinforced cement mortar: a statistical approach. Construction and Building Materials, 38, 776-784.

E. K. Schrader, Formulating Guidance for testing of fibre concrete in ACl Committee 544, in Testing and Test. Methods of Fibre Cement Composites, R. N. Swamy, Ed., New York, Longman Inc., 1978.

Jarabo, R., Fuente, E., Monte, M. C., Savastano, H., Jr., Mutje, P., \& Negro, C. (2012). Use of cellulose fibers from hemp core in fiber-cement production. Effect on flocculation, retention, drainage and product properties. Industrial Crops and Products, 39(1), 89-96.

Mansur, M. A., Wee, T. H., \& Cheran, L. S. (1999). Crushed bricks as coarse aggregate for concrete. ACI Materials Journal (American Concrete Instute), 96(4), 478-484.

Mansur, M. A., \& Aziz, M. A. (1982). A study of jute fibre reinforced cement composites. International Journal of Cement Composites and Lightweight Concrete, 4(2), 75-82.

Meddaha, M. S., \& Bencheikh, M. (2009). Properties of concrete reinforced with different kinds of industrial waste fibre materials. Construction and Building Materials, 23, 3196-3205.

Mohammad Zakaria, Mashud Ahmed, Md. Mozammel Hoque, Abdul Hannan. (2015). Effect of jute yarn on the mechanical behavior of concrete composites. SpringerPlus 4 (1).

Mohammed, T. U., Hasnat, A., Awal, M. A., \& Bosunia, S. Z. (2014). Recycling of brick aggregate concrete as. coarse aggregate. Journal of Materials in Civil Engineering, 27(7), B4014005.

Ramakrishna, G., \& Sundararajan, T. (2005). Impact strength of a few natural fibre reinforced cement mortar. Cement \& Concrete Composites, 27(5), 547-553.

Rashid, M. A., Hossain, T., \& Ariful Islam, M. (2009). Properties of higher strength concrete made with crushed brick as coarse aggregate. Journal of Civil Engineering (IEB), 37(1), 43-52.

Rizkalla, S., \& Hassan, T. (2002). Effectiveness of FRP for strengthening concrete bridges. Structural Engineering International, 12(2), 89-95. 
Savastano, H., Santos, S. F., Radonjic, M., \& Soboyejo, W. O. (2009). Fracture and fatigue of natural fiber-reinforced cementitious composites. Cement Concrete composites, 31(4), 232-243.

Shimizu, G., \& P. Jr. Jorillo. (1992). Coir fibre reinforced cement based composite. Part one: microstructure and properties of fibre-mortar. Edited by R.N. Swamy. London: Proc. Fourth RILEM International Symposium on Fibre Reinforced Cement and Concrete, 1080-1095.

Thakur, V. K., Thakur, M. K., \& Gupta, R. K. (2014). Graft copolymers of natural fibers for green composites. Carbohydrate Polymers, 104, 87-93.

Xie, Y. J., Hill, C. A. S., Xiao, Z. F., Militz, H., \& Mai, C. (2010). Silane coupling agents used for natural fiber polymer composites: a review. Composite Part A: Applied Science And Manufacturing, 41, 806-819.

\section{Submit your manuscript to a SpringerOpen ${ }^{\circ}$ journal and benefit from:}

- Convenient online submission

- Rigorous peer review

- Immediate publication on acceptance

- Open access: articles freely available online

- High visibility within the field

- Retaining the copyright to your article

Submit your next manuscript at $\boldsymbol{s p r i n g e r o p e n . c o m ~}$ 